\title{
Dinâmicas atuais da enfermagem em Portugal: a representação dos enfermeiros
}

\author{
Current dynamics of nursing in Portugal: nurses' representations
}

Dinámicas actuales de la enfermeria en Portugal: la representación de los enfermeros

\author{
Felismina Rosa Parreira Mendes', Maria de Fátima Mantovani" \\ 'Universidade de Évora. Escola Superior de Enfermagem. Évora, Portugal \\ "Universidade Federal do Paraná. Departamento de Enfermagem. Curitiba, PR
}

Submissão: 12/12/2008

Aprovação: 05/01/2010

\section{RESUMO}

Trata-se de pesquisa Qualitativa, com o objetivo de identificar as representações dos enfermeiros acerca das dinâmicas atuais da profissão, os marcos de sua evolução e as perspectivas futuras, realizada com vinte enfermeiros de Évora-Portugal, em abril/ maio de 2009, através de testemunhos narrativos. A formação ao longo dos anos e a Ordem dos Enfermeiros foram representadas como pilares centrais na construção da identidade profissional. A autonomia integra o cotidiano de cuidados, mas as Questões hegemônicas de poder na equipe de saúde continuam a pautar a atuação dos enfermeiros e a balizar o seu auto e heterorreconhecimento profissional e social. As perspectivas futuras se direcionam para a empregabilidade, carreira e se consubstanciam na esperança de uns e na incerteza de outros.

Descritores: Prática profissional; Autonomia profissional; Enfermagem

\section{ABSTRACT}

This research study, with a Qualitative approach was carried out aiming to identify nurses' representation on current professional dynamics, evolutionary landmarks and the future outlook for Portuguese nursing with twenty nurses from Évora, Portugal, in April / May of 2009, through narrative testimony. Qualification obtained along the years as well as the Nurses' Association were mentioned as the central representative pillars in order to build up professional identity. Autonomy is part of daily caring routine, however hegemonic power issues in the health team still ground nurses' action and underpin their self and peer professional and social recognition. Future outlook addresses issues such as employment, career uncovering hope for some and uncertainty for others.

Key words: Professional practice; Professional autonomy; Nursing.

\section{RESUMEN}

Se trata de pesquisa cualitativa con el objeto de identificar las representaciones de los enfermeros sobre las dinámicas actuales de la profesión, los hitos de su evolución y las perspectivas futuras, realizadas con veinte enfermeros de Évora en Portugal entre los meses de abril y mayo de 2009, por medio de declaraciones. La formación a lo largo de los años y la Orden de los Enfermeros fueron mostrados como pilares principales en la construcción de la identidad profesional. La autonomía integra los cuidados diarios, así como las cuestiones de hegemonía de poder en el equipo de salud que continúan a balizar la actuación de los enfermeros y a nortear su auto y heteroreconocimiento profesional y social. Las perspectivas futuras se direccionan para la empregabilidad, carrera y se consustancian en la esperanza de unos y la incertidumbre de otros.

Descriptores: Práctica profesional; Autonomía profesional; Enfermería.

AUTOR CORRESPONDENTE Felismina Rosa Parreira Mendes. Largo Senhor da Pobreza, s.n. CEP: 7000-81 I. Évora, Portugal.

E-mail:fm@uevora.pt 


\section{INTRODUÇÃO}

Ao longo dos últimos anos, a enfermagem em Portugal experimentou uma grande evolução na formação dos profissionais e na consequente melhoria da Qualidade dos cuidados, no respeito ao aumento da complexidade e no reconhecimento desta atividade profissional. Em relação ao processo de profissionalização, a enfermagem portuguesa emerge como um caso único na Europa, na medida em Que desde o final da década de setenta do século XX possui um único profissional, a partir de um ciclo único de formação(l).

A carreira única para todos os enfermeiros e a definição das cinco categorias profissionais, entre as Quais a de enfermeiro especialista, foram instituídas em 1981 pelo Decreto-Lei no 305/ $8 I^{(2)}$. No entanto, Quatro anos mais tarde, o Decreto-Lei $n^{\circ} 178 /$ 85 , de 23 de maio $^{(3)}$, veio melhorar as especificações anteriores relativas à carreira, conduzindo à assunção dos enfermeiros aos corpos especiais da função pública, e, três anos mais tarde, as escolas de enfermagem passaram a pertencer ao ensino politécnico, Quando foram criados o Curso Superior de Enfermagem e os Cursos de Estudos Superiores Especializados em Enfermagem, por meio do Decreto-Lei no 480/88, de 27 de agosto $^{(4)}$.

A década de 90 do século XX trouxe muitas conquistas aos enfermeiros portugueses em relação ao regime de trabalho, Que passou a ser de 35 horas semanais, e à definição de três áreas de atuação para o enfermeiro: prestação de cuidados, gestão e assessoria $^{(5)}$. Foi também nesta altura, 1992, Que se iniciaram os primeiros mestrados em Ciências de Enfermagem. Posteriormente, surgiram os programas de doutoramento em enfermagem, e atualmente existem três programas regulares de doutoramento em enfermagem (dois oferecidos por universidades públicas - Lisboa e Porto - e um oferecido por uma universidade privada - Lisboa).

O Regulamento do Exercício Profissional dos Enfermeiros (REPE), estabelecido pelo Decreto-Lei $n^{0}$ 161/96, de 4 de setembro(6), veio responder a uma lacuna legislativa Quanto ao exercício profissional da enfermagem, Que não dispunha de um instrumento jurídico contendo a sua regulamentação, e este possibilitou a clarificação de conceitos, intervenções e funções, bem como os aspectos básicos dos direitos e deveres dos enfermeiros.

Em 1998, o momento ambicionado por várias gerações de enfermeiros tornou-se uma realidade. Em 21 de abril foi publicado no Diário da República o Decreto-Lei no $104 / 98^{(7)}$, documento Que permitiu a criação da Ordem dos Enfermeiros (OE), responsável pela regulamentação e disciplina da prática dos enfermeiros. Esse decreto contemplou, em anexo, o Estatuto da OE, documento Que integra o Código Deontológico do Enfermeiro.

A regulação profissional, pelos poderes Que, através da Ordem, foram devolvidos à profissão, constituiu-se como pilar do desenvolvimento da enfermagem e instrumento de promoção da Qualidade dos cuidados. Nela destaca-se a perspectiva de um novo Modelo de Desenvolvimento Profissional (MDP)' ancorado na certificação de competências. Com a OE foram estabelecidas condições para a consolidação da autonomia responsável da profissão de enfermagem. Entre as atribuições desta, destacam-se: promover a defesa da eualidade dos cuidados de enfermagem; regulamentar e controlar o exercício da profissão de enfermeiro e assegurar o cumprimento das regras de ética e deontologia profissional( $^{(7-8)}$.

Finalmente, em 1999, com o Decreto-Lei no 353/99, de 3 de setembro $^{(9)}$, a formação em enfermagem passou a ser assegurada pelo Curso de Licenciatura em Enfermagem (Quatro anos), com um acréscimo de competências ao nível da gestão de serviços de saúde, formação e investigação em enfermagem.

Atualmente, em Portugal ${ }^{(1)}$, os enfermeiros mobilizam a dimensão técnico-intelectual no Quotidiano do cuidado, fazendo-o a partir de uma formação superior, encuadrada jurídica, ética e cientificamente e regulada pelo próprio grupo profissional. Estamos, assim, perante um grupo profissional Que adQuiriu Qualificação para não só conceber e produzir conhecimento, como também transferir o conhecimento científico para a atividade cotidiana.

No contato com estes profissionais percebe-se ainda Que, fruto da evolução do país ou da profissão de enfermagem, eles vivem momentos de mudança, Que se consubstanciam essencialmente nas alterações ao MDP dos enfermeiros e nos novos modelos de contratualização e vínculos laborais Que emergiram nos últimos anos. É Que o Estado, principal empregador dos profissionais de enfermagem e garantia de emprego para a vida, deu lugar a um mercado saturado e à precarização contratual, confrontando-se os jovens recém-formados com dificuldades crescentes, tanto na inserção no mercado de trabalho, Quanto na obtenção de estabilidade no emprego.

Os aspectos supramencionados podem ter influenciado não só a inserção destes profissionais, como a representação que eles têm acerca da atividade laboral e da própria profissão, ocasionadas pelas mudanças sofridas ao longo dos últimos anos. Portanto, o objetivo deste trabalho foi identificar as representações dos enfermeiros portugueses acerca das dinâmicas atuais da profissão, dos marcos de sua evolução e das perspectivas futuras da enfermagem.

\section{MÉTODO}

Estudo de natureza Qualitativa realizado no período de abril/ maio de 2009, ancorado nas representações sociais (RS) como suporte metodológico de análise. As $\mathrm{RS}^{(10)}$, são modos de pensamento a partir dos Quais os sujeitos elaboram significações ligadas a condutas individuais e coletivas mediante a criação de categorias cognitivas e relações de sentido Que são exigidas e podem funcionar como atributo de grupo na identificação, aceitação ou rejeição.

Neste sentido, as representações sociais referem-se à maneira de o indivíduo pensar e perceber o cotidiano, constituindo-se em um conjunto de imagens Que permite ao mesmo interpretar e dar sentido à sua vida ${ }^{(1)}$, e são uma forma de conhecimento socialmente elaborado e compartilhado e Que tem como finalidade a interpretação de uma realidade comum de um dado grupo social, neste caso os enfermeiros.

Para Gazzinelli ${ }^{(12)}$, constituem um conjunto aberto e heterogêneo, continuamente refeito, ampliado e transformado durante as interações indivíduo-indivíduo e indivíduo-sociedade. As $\mathrm{RS}^{(13)}$ são um "conjunto organizado e hierareuizado de julgamentos, atitudes e informações Que um determinado grupo elabora a respeito de um objeto", interiorizadas e compartilhadas por este grupo.

Participaram do estudo 20 enfermeiros de diversos serviços de saúde do distrito de Évora, em Portugal, Que, durante o ano de 
2009, frequentaram ou concluíram cursos de pós-graduação em enfermagem e Que aceitaram participar do estudo mediante os testemunhos narrativos, nos Quais se pronunciaram sobre os marcos profissionais, as dinâmicas atuais da profissão e suas perspectivas futuras. Os preceitos éticos de sigilo, anonimato e consentimento esclarecido foram obedecidos. Os trechos dos depoimentos utilizados no artigo são identificados com Enf 1, 2... 20. A análise de conteúdo dos depoimentos foi realizada segundo os preceitos de $\operatorname{Bardin}^{(14)}$.

\section{RESULTADOS E DISCUSSÃO}

Os participantes deste estudo possuem média de idade de 38,7 anos, 16 são do sexo feminino e Quatro do masculino, a média de atuação profissional é de 14,8 anos (variando de 2 a 18 anos), dois possuem mestrado, e a área de exercício divide-se entre o hospital, para dez deles, e os cuidados comunitários, igualmente para dez profissionais.

Os principais marcos da profissão de enfermagem nos últimos trinta anos foram representados pela evolução da formação e pela criação da Ordem dos Enfermeiros (OE).

Na evolução da formação destacam a integração do ensino de enfermagem no nível do Ensino Superior Politécnico em $1988^{(4)} \mathrm{e}$, mais tarde, a criação do Curso de Licenciatura em Enfermagem ${ }^{(9)} \mathrm{e}$ dos Cursos de Pós-Licenciatura de Especialização em Enfermagem, regulamentados em 2002. Todos os enfermeiros têm conhecimento e nominam as principais transformações da formação como pontos marcantes da profissão.

A integração do Ensino de Enfermagem no Ensino Superior com o reconhecimento profissional - Curso de Licenciatura em Enfermagem e Pós Licenciatura... A possibilidade de Doutoramentos em Enfermagem e a criação da Ordem dos Enfermeiros (Ent. 14).

Quando se pronunciam sobre os marcos Que consideram mais importantes para o avanço da profissão de enfermagem em Portugal, os enfermeiros voltam a centrar-se naqueles que foram anteriormente identificados como os principais marcos da profissão - a criação da OE, a formação e o REPE. A OE e o REPE são concebidos como marcos definidores do seu papel Que vieram a conferir significado e unidade ao seu trabalho/prática.

...o investimento de cada um na formação profissional permite actuar com conhecimento e segurança e a autonomia são ganhos Que a custo temos obtido (Ent. 2).

... a aprovação do Estatuto da OE permitindo a auto-regulação e a integração do ensino de enfermagem no ensino superior, constituem dois marcos decisivos para o crescimento autónomo da enfermagem (Ent. 18).

A Licenciatura Enfermagem, o REPE e a criação da Ordem dos Enfermeiros (Ent. 16).

Ao se pronunciarem sobre a importância da $\mathrm{OE}$, os profissionais unanimemente identificaram o valor de Que se reveste para a enfermagem através da sua função reguladora, como também na promoção da Qualidade dos cuidados e na explicitação de competências e dos direitos e deveres profissionais/Código Deontológico.

Estatuto da OE tem como desígnio fundamental promover a defesa da Qualidade dos cuidados de Enfermagem prestados à população, bem como o desenvolvimento, a regulamentação e o controlo do exercício da profissão de enfermeiro, assegurando a observância das regras de ética e deontologia profissional. A auto-regulação profissional é um garante da protecção do interesse público e do bem comum, tanto no acesso à prática profissional, como na monitorização e no desenvolvimento da prática, na regulamentação e no controlo do exercício, sendo disso exemplo os Padrões de Qualidade definidos em 2002 e as Competências dos Enfermeiros de Cuidados Gerais, em 2003 (Ent. 18).

Observa-se Que os enfermeiros não se atêm aos aspectos de fiscalização do exercício, mas têm a noção correta de todos os preceitos e diretrizes do órgão de classe, e que, principalmente no Que concerne à criação da $\mathrm{OE}$, têm a representação de Que esta é um pilar da profissão, pois regulamenta e fiscaliza.

Além disso, como afirmam vários autores ${ }^{(8,15)}$, a publicação do REPE iniciou um novo ciclo na profissão de enfermagem Que aponta claramente para princípios de atuação, Que encontram o seu fundamento numa moral de cooperação e respeito mútuos, baseada na igualdade, na reciprocidade, nas relações humanas e em acordo ou contratos sociais. Como refere D'Espiney ${ }^{(16)}$, o REPE assumiu uma centralidade estratégica na afirmação da enfermagem como profissão e no reconhecimento estatal do poder deste grupo profissional para se autorregular e confirmar a sua autonomia.

A valorização da formação é igualmente representada como motriz da profissão. Como salienta Stedile ${ }^{(17)}$, a formação traduzse num momento privilegiado de construção do saber Que estimula a consolidação de um corpo de conhecimento próprio da enfermagem, com repercussões na identidade do enfermeiro e na visibilidade do corpo de conhecimento produzido.

Porém, como salientam algumas enfermeiras, a formação não é suficiente. Ou seja, por si só não imprime novas dinâmicas a enfermagem portuguesa, nomeadamente em termos do seu reconhecimento social. De acordo com D'Espiney (16) "ao profissional não basta já ter o título. Este necessita provar, na acção e em situação, a sua competência para intervir de forma adeQuada. É o próprio Que, por via do modo como intervém, conQuista a legitimidade para a sua acção".

No entanto, se muitos enfermeiros optam por realizar formação contínua, como é o caso dos cursos de Estudos Superiores Especializados em Enfermagem, é porque buscam melhores condições de trabalho e salário, possibilidade esta só obtida mediante o reconhecimento dessa formação e o recebimento de títulos profissionais pela $\mathrm{OE}$.

A formação pode também ser percebida como relevante para o aperfeiçoamento profissional e para a conQuista de novos espaços de atuação, Quer dando sentido à prática profissional, Quer no estabelecimento do espaço a partir do Qual seriam exercidas e legitimadas as relações de poder com a equipe de saúde e com a 
sociedade. Neste sentido, a importância atribuída pelos enfermeiros ao conhecimento científico deve ser entendida como aspecto instrumental e necessário ao estabelecimento de um campo profissional autônomo ${ }^{(18)}$.

Em termos de dinâmicas atuais da profissão, destacam-se a centralidade do cuidar com maior ênfase no componente relacional e o consequente afastamento do modelo-biomédico

O facto de cuidar em toda a essência do cuidar, revela-se uma mais-valia, tanto pessoal, como profissional. Torna-nos pessoas activas dinâmicas e com um sentido de responsabilidade, pelos outros, essencial e gratificante (Ent. 6).

Os modelos de gestão eram baseados em normativos, estando hoje configurados em objectivos e resultados (Ent. 18).

Como salienta Amendoeira ${ }^{(1)}$, parece ter existido uma capacidade dos enfermeiros portugueses em mobilizarem no cotidiano a dimensão técnico-intelectual, fruto de percursos formativos consolidados, onde a visão integradora cimentada na dimensão técnico-relacional passa a caracterizar a essência do cuidado de enfermagem.

Também a definição de competências (adaptadas do ICN) pela Classificação Internacional da Prática de Enfermagem (CIPE) assume lugar privilegiado na caracterização das dinâmicas profissionais atuais.

Tem uma linguagem própria, constantemente actualizada e editada por um conselho internacional para a prática da enfermagem (ICN designada (CIPE) A utilização de sistemas de informação próprios, a gestão do conhecimento e a competência são pilares ao desenvolvimento da prática da investigação (Ent. 14)

É clara a adesão e valorização de parâmetros definidores, comparativos e promotores da visibilidade da profissão de Que são exemplo o perfil de competências elaborado pela OE. Os instrumentos orientadores da prática profissional são apreendidos e reconstruídos como operadores Que concorrem para definirem as dinâmicas atuais da profissão.

A autonomia está sempre presente no discurso destes profissionais e emerge como um dos traços centrais da profissão na atualidade, mesmo Quando apresentam posições contraditórias sobre a mesma (os Que afirmam Que ela já é um fato no cotidiano e aQueles Que defendem Que ainda não têm uma atuação autônoma). Para os primeiros, a autonomia de Que usufruem na prestação de cuidado é indissociável da área onde exercem funções, ou seja, percebem o trabalho na comunidade como aquele onde os enfermeiros dispõem de mais autonomia, por oposição aos serviços hospitalares.

Penso que o trabalho nos cuidados de saúde primários... é de uma grande autonomia para os enfermeiros. Nos cuidados hospitalares é mais dependente da parte médica (Ent. 4).

A saudificação da sociedade a Que se tem assistido nos últimos anos, com a mudança do discurso tradicionalmente centrado na doença para a saúde, através da promoção da saúde e dos estilos de vida saudáveis, faz emergir a centralidade dos cuidados comunitários com a prestação de cuidados globais aos indivíduos e famílias centrados na comunidade e nas famílias ${ }^{(16,19)}$. Assim, Quer o próprio território habitual das profissões, Quer a finalidade dos próprios cuidados sofrem uma deslocação da esfera de influência médica para serem reequacionados a partir da autonomia obtida e das transformações reQueridas/exigidas com esta mudança de paradigma. Este fato pode justificar a atribuição/representação Que é feita de maior autonomia aos enfermeiros comunitários.

Para alguns enfermeiros, a autonomia alcançada está associada à criação da $\mathrm{OE}$ e aos conhecimentos e competências de cada um.

A auto-regulação profissional permite-nos desenvolver a nossa profissão de forma autónoma. $O$ exercício desse direito não é uniforme e está condicionado a variáveis que vão desde as competências e conhecimentos de cada profissional... A minha percepção é a de Que é mais fácil exercer autonomamente em contexto de centro de saúde do que em meio hospitalar (Ent. 18).

A autonomia é concebida como extrínseca ao próprio grupo profissional, no sentido de Que não é conQuistada de dentro para fora (através da consolidação da identidade profissional), mas obtida através de uma entidade exterior à prática cotidiana, isto é, de fora para dentro - pelos mecanismos de autorregulação da $\mathrm{OE}$. Igualmente importante nos testemunhos recolhidos é o caráter individual Que esta autonomia assume. É remetida para cada profissional a possibilidade de alcançá-la, através de trajetos e esforços próprios, ou seja, ela é concebida a partir da sua dimensão individual, exigindo um esforço cotidiano, em vez de se impor como uma conQuista profissional. O seu caráter precário é manifesto e as ameaças são contínuas.

Os enfermeiros estão mais autónomos, mas continuam a lutar contra a supremacia médica (Ent. 11).

A Questão da submissão às ordens médicas aparece como problema à autonomia dos enfermeiros, fato Que pode estar atrelado ao início da profissão que nasceu ligada aos hospitais e devido à necessidade sentida pelos médicos da formação de pessoal capacitado para cuidar dos doentes. Aos médicos competia exclusivamente o exercício dos cargos e das funções de direção técnica dos serviços, enQuanto Que aos enfermeiros cabia prestar os cuidados à cabeceira dos doentes, com uma postura caridosa, executando as tarefas prescritas pelo médico e reproduzindo ações complementares à prática médica ${ }^{(20-21)}$.

Historicamente, os enfermeiros sempre se confrontaram com uma profissão autônoma, organizada e legitimada no seu poder. Esta autonomia, cimentada num saber socialmente reconhecido e protegido, conferiu à profissão médica o monopólio profissional e assegurou-lhe uma incontestável posição de dominação no interior de um processo de divisão de trabalho na saúde ${ }^{(22)}$. Essa percepção mantém-se até os dias atuais. Assim, para os enfermeiros afirmarem efetivamente a sua autonomia, a partir dos múltiplos referenciais Que dominam a enfermagem portuguesa na atualidade, necessitam construir e reconstruir os seus processos de trabalho e, através 
deles, definir e redefinir a sua profissionalidade.

Existem, no entanto, aQueles Que, exprimindo a sua frustração, continuam a representar a enfermagem como uma profissão à procura da sua própria identidade e a lutar pelo seu reconhecimento social, na Qual impera a burocracia e a incerteza, ligadas aos novos modelos de gestão, às Questões da certificação, da Qualidade dos serviços e dos cuidados e à própria avaliação/determinação das necessidades de cuidados de enfermagem, implementados nos últimos anos nas organizações de saúde portuguesas.

Ser enfermeiro hoje é não saber o Que vai acontecer amanhã, tudo está em mudança, o esforço não é premiado, estamos sobrecarregados... (Ent. 2).

A navegar num vazio sem objectivo definido a longo prazo...(Ent. 12).

Para Guitton ${ }^{(23)}$, a inexistência da identidade profissional do enfermeiro deve-se a uma percepção conflituosa de si mesmo e da sua prática, tal como a uma não circunscrição de seu espaço e à indefinição de papéis Que ainda se faz sentir.

Também Villa e Cadete ${ }^{(24)}$ salientam as dificuldades dos enfermeiros no estabelecimento de um espaço próprio de exercício de poder, enQuanto instância geradora da forma como a profissão se relaciona com a sociedade, com a equipe de saúde e com as instituições, públicas ou privadas. A enfermagem, para Bueno ${ }^{(25)}$, só poderá adeuirir plena autonomia euando o cuidado passar a ser visto como uma esfera privilegiada na área da saúde, tanto do ponto de vista científico como prático. Considera, ainda, Que esta apropriação extrapola a vontade individual do enfermeiro ou a vontade coletiva da profissão e Que apenas uma mudança de paradigma científico poderá conferir ênfase ao cuidado. Neste contexto, o cuidar emerge como operador simbólico na homogeneização das práticas e como referencial da identidade profissional $^{(26)}$.

Da mesma forma, eles não deixam de manifestar as suas dúvidas sobre a Qualidade dos cuidados prestados, já Que cada vez mais essa parece ser suplantada pela Quantidade, numa época em Que os novos modelos de gestão das organizações de saúde precisam apresentar resultados Que sustentem e mantenham o financiamento governamental.

A prestação de cuidados de acordo com o modelo de gestão Que impera é sobretudo virada para aspectos Quantitativos de eficácia e poupança de recursos humanos e materiais, do Que para a Qualidade dos cuidados de enfermagem e bem-estar do doente e enfermeira (Ent. 14).

A empresarialização do sistema de saúde português, com efeitos claros no cotidiano de trabalho dos enfermeiros, domina os discursos daqueles Que representam as atuais dinâmicas da profissão, fortemente influenciadas por fatores negativos, como o não reconhecimento da enfermagem e as Questões da carreira. Nos discursos seguintes, ficam evidenciadas as dificuldades associadas à progressão na carreira, a diminuição de recursos humanos na prestação dos cuidados e a alteração dos vínculos contratuais.
A pouca visibilidade Que a nossa profissão e a importância desta na sociedade. Aspecto este Que dificulta a nossa profissão, a nossa luta diária e o reconhecimento por parte dos outros. Não progressão na carreira... a valorização da Quantidade dos cuidados em detrimento da Qualidade e a diminuição dos recursos humanos (Ent. 6).

Uma crescente instabilidade nas condições de vinculação laboral e um percurso indefinido com perspectivas de desenvolvimento profissional bastante incertas (Ent. 18).

O fraco reconhecimento social da profissão volta a ser apontado como uma dificuldade por estes enfermeiros, os Quais assinalam este aspecto como uma das dinâmicas Que marcam a enfermagem portuguesa na atualidade. Sobre o reconhecimento social da profissão, destacam-se os contributos de Dal Pai et al ${ }^{(28)}$, Que salientam a importância da organização política da profissão, considerando Que através do fortalecimento desta se alcança a representatividade social e se conquista um novo paradigma na prática discursiva sobre a atuação do profissional enfermeiro e sobre o seu saber.

Quando analisam a perspectiva do futuro da profissão, os enfermeiros mostram-se reticentes e pouco otimistas. Os sentimentos de pessimismo e de incerteza resultam das transições e reformas em curso tanto na profissão como na carreira e no Modelo de Desenvolvimento Profissional proposto pela OE e atualmente em discussão pública.

Perspectivo a enfermagem como uma profissão cada vez mais sobrecarregada de burocracias, em que cada vez mais se perde tempo com papéis, em detrimento de estar junto do utente/ doente. Perspectivo os enfermeiros com elevados níveis de formação mas não reconhecidos (em termos de carreira profissional) remunerados como tal. Perspectivo a enfermagem com taxas altas de desemprego, situação Que já se começa a notar (Ent. 5).

Observa-se Que, se por um lado os enfermeiros consideram a importância da OE como reguladora da prática profissional e responsável por garantir cuidados de Qualidade, por outro não vislumbram um ancoradouro estável Que lhes garanta as bases de edificação e manutenção da identidade profissional. Consideram a possibilidade de capacitação como um ganho, mas Que também pode gerar sentimentos de frustração, ao agudizar as disputas/ confrontos na equipe de saúde e ao manter os fracos índices de reconhecimento social da profissão (traduzíveis na diferença mantida entre o nível de formação alcançado e a remuneração obtida). E, neste contexto, o pilar em Que se ancoraram nos últimos dez anos - a OE - já não se revela capaz de apaziguar os medos e os receios de um futuro sem esperança.

Ao enunciarem as principais transformações futuras desejadas, salientam o reconhecimento social e remuneratório da enfermagem, a redefinição da carreira e a estabilidade profissional. Também as Questões Que afetam a prestação de cuidados são alvo de mudanças expectáveis.

Progressão na carreira... Reconhecimento da profissão e 
importância da sua existência, para a recuperação da saúde, dos indivíduos necessitados... Remuneração consoante as Qualificações profissionais... Reconhecimento a nível social dos deveres e dos direitos dos indivíduos. Aquisição de autonomia, relativamente à prestação dos cuidados e existência de mais recursos humanos, consoante as necessidades efectivas de cada instituição de saúde e dos respectivos serviços (Ent. 6).

As Questões da instabilidade laboral e da carreira (atualmente em negociação entre governo e sindicatos e onde se perspectivam mudanças profundas) e, mais uma vez, o reconhecimento social da profissão são os desejos enunciados. Parece claro para os enfermeiros Que, sem o tão almejado reconhecimento social, dificilmente conseguirão adQuirir a estabilidade sonhada e uma carreira e um estatuto remuneratório Que traduza no cotidiano aQuilo Que são as exigências científicas e técnicas da prática profissional atual.

Estas expectativas futuras revelam uma frustração latente Que se expressa no reconhecimento de Que a formação de nada serve se não for socialmente reconhecida; caso contrário, este investimento formativo só contribuirá para aumentar os níveis de descontentamento dos enfermeiros ${ }^{(28)}$.

\section{CONSIDERAÇÕES FINAIS}

A enfermagem portuguesa, nas concepções dos enfermeiros, tem hoje um status, obtido nos últimos anos do século XX, cujo principal responsável foi a criação da Ordem dos Enfermeiros, a formação (grau acadêmico de nível superior) e o REPE. Estes marcos consubstanciaram-se em ganhos para os usuários, com o modelo biomédico dando lugar ao cuidar e a uma visão mais integral do ser humano, e abriram novas possibilidades à profissão, nomeadamente a partir dos regulamentos próprios, das novas nomenclaturas e diretrizes Que emergiram e Que se impuseram na prática cotidiana com a publicação do REPE e a criação da OE.

Os enfermeiros parecem dividir-se entre os Que percebem a formação adQuirida ao longo dos anos e a OE como pilares centrais para a construção da sua identidade profissional e aqueles Que parecem transportar a instabilidade laboral e de carreira para as Questões centrais da profissão.

A formação, a Que aderem continuamente, pode contribuir para facilitar o acesso aos diferentes graus da carreira, mas tem se revelado incapaz de funcionar como catalisadora de sua identidade, afirmação e reconhecimento social. De fato, em Portugal, a prática profissional convive com tensões entre a constante especialização da profissão, gerando áreas específicas de saber/fazer e dando origem a competências Que não obtêm o reconhecimento interpares e social desejado e nas Quais o valor social atribuído à prática cotidiana do enfermeiro fica sempre aQuém das expectativas.

A crescente instabilidade laboral, associada à empresarialização da saúde, não auxilia a mudança substancial no reconhecimento da profissão pela sociedade, nem na melhoria da prestação de cuidados à população. Pelo contrário, tornou a profissão mais burocratizada, menos reconhecida e mal remunerada.

Se para os enfermeiros a autonomia já integra o seu cotidiano de cuidados, para outros as Questões hegemônicas de poder na equipe de saúde continuam a pautar a atuação dos enfermeiros e a balizar o seu auto e heterorreconhecimento profissional e social. Por isso, a procura da identidade profissional e do reconhecimento social é uma Questão central à realidade destes profissionais. Os significados implícitos à autoimagem são indissociáveis e estão intimamente ligados às representações sociais da profissão e ao não reconhecimento Que cotidianamente experienciam. Parece dominar uma clara inconsistência de status resultante do gap entre a formação e os saberes de Que são detentores e o poder a Que têm acesso. Os enfermeiros não assumem explicitamente uma posição periférica no campo da saúde, mas, implicitamente, representam-se socialmente posicionados na periferia do sistema.

As perspectivas futuras se direcionam para a empregabilidade, a carreira e a inserção da profissão nos vários níveis de poder. Estes pontos estão diretamente ligados à capacidade dos enfermeiros em demonstrar a importância socioeconômica da profissão, através da delimitação de ações socialmente importantes, necessárias e exclusivas da sua profissionalidade. Mais uma vez se verifica Que as Questões da autonomia e do domínio e da delimitação do próprio espaço de atuação são centrais para o reconhecimento futuro da profissão. Este futuro transporta a esperança de uns e cristaliza os receios e a incerteza de outros.

\section{Agradecimentos}

Aos enfermeiros que colaboraram com esta investigação, ao Centro de Investigação de Ciências e Tecnologias da Saúde/CICTS da Universidade de Évora, na pessoa de Eugénia Simões, responsável pela digitação dos dados, e à Coordenação de Aperfeiçoamento de Pessoal de Nível Superior (CAPES) pela bolsa de pós- doutorado concedida a uma das autoras.

\section{REFERÊNCIAS}

I. Amendoeira I. Entrevista. Sinais Vitais 2005; (63): 5-12.

2. Portugal. Decreto-lei 305/8I de 12 de novembro. Aprova o regime legal da carreira de enfermagem e respectivas alterações. Diário da República de Portugal, I Série, Lisboa. 12 de novembro de 1981 .

3. Portugal. Decreto-lei $n^{\circ} 178 / 85$ de 23 de Maio. Aprova a revisão da carreira de enfermagem. Diário da República de Portugal, I Série, Lisboa. 23 de Maio de 1985.

4. Portugal. Decreto-Lei n. ${ }^{\circ}$ 480/88, de 27 de agosto. Estabelece a integração do ensino superior de enfermagem no ensino superior politécnico. Diário da República de Portugal, I Série,

Lisboa. 27 de agosto de 1988.

5. Portugal. Decreto-lei no $437 / 9$ I de 8 de novembro. Estabelece a nova Carreira de Enfermagem. Diário da República de Portugal, I Série, Lisboa. 8 de Novembro de 1991.

6. Portugal. Decreto-Lei no 161/96 de 4 de setembro. Regulamento do exercício profissional dos enfermeiros (REPE). Diário da República de Portugal, I Série, Lisboa. 4 de setembro de 1996.

7. Portugal. Decreto-lei no 104 de 21 de abril de 1998. Cria a Ordem dos Enfermeiros. Diário da República de Portugal I Série, Lisboa. 2 I de abril de 1998. 
8. Silva DM.Correntes de pensamento em ciências de enfermagem Millenium - Revista do ISPV. 2002; 26 Disponível em: http:// www.ipv.pt/millenium/millenium26/26_24.htm.

9. Portugal. Decreto-lei no 353/99 de 3 de setembro. Confere o grau de Licenciatura ao Curso de Enfermagem. Diário da República de Portugal, I Série, Lisboa. 3 de setembro de 1999.

10. Herzlich C. A problemática da representação social e sua utilidade no campo da doença. Physis: Rev. Saúde Coletiva. 2005; 15(sup): 57-70.

11. Moscovici S. Representações sociais. Petrópolis: Vozes, 2003.

12. Gazzinelli MF, Gazzinelli A, Reis DC, Penna CNM. Educação em saúde: conhecimentos, representações sociais e experiência da doença. Cad Saúde Pública 2005; 2 I (1): 200-6.

13. Abric JC. A abordagem estrutural das representações sociais. In: Moreira ASP, Oliveira DC, organizadores. Estudos interdisciplinares de Representação Social. Goiânia: AB, 1998 ; p.27-38.

14. Bardin L. Análise de conteúdo. Lisboa: Ediçoes 70; 1977.

15. Espirito Santo C. As competências dos enfermeiros e as práticas de enfermagem: contributos para a mudança. Rev Referência 1999; (3):53-8.

16. D'Espiney L. Enfermagem: de velhos percursos a novos caminhos. Rev Ciências Educação 2008; (6):7-20.

17. Stedile NLR. Ensino de enfermagem: momento privilegiado de construção do conhecimento. Acta Paul Enferm 2002; 15(3): 79-86.

18. Gomes MT, Oliveira DC. Espaço autônomo e papel próprio: representações de enfermeiros no contexto do binômio saúde coletiva-hospital. Rev Bras Enferm 2008; 6 I (2): 178-85.

19. Fitzpatrick M. The tyranny of health. Doctors and the regulation of lifestyle. London: Routledge; 2001.

20. Nogueira MA. História da enfermagem. $2^{\mathrm{a}}$ ed. Porto: Salesianas, 1990.

2 1. Witt RR, Almeida MCP. Competências dos profissionais de saúde no referencial das funções essenciais de saúde pública: contribuição para a construção de projetos pedagógicos na enfermagem. Rev Bras Enferm 2003; 56(4): 433-8.

22. Freidson E. Professional dominance: the social structure of medical care. New York: Atherton Press; 1970.

23. Guitton B, Figueirdo N, Porto I. A passagem pelos espelhos: a construção da identidade profissional da enfermeira. Niterói: Ed. Intertexto; 2002.

24. Villa EA, Cadete MMM. A Cultura Institucional como Determinante da Prática Educacional do Enfermeiro. TextoContexto Enferm 2000; 9(3): 15-32.

25. BuenoFG. O enfermeiro e a construção da autonomia profissional no processo de cuidar. Rev Bras Enferm 2006; 59(2): 222-7.

26. Lopes N. Recomposição profissional da enfermagem: estudo sociológico em contexto hospitalar. Coimbra: Quarteto Editora; 2001 .

27. Dal Pai D, Schrank G, Pedro ENR. O enfermeiro como ser sócio-político: refletindo a visibilidade da profissão do cuidado. Acta Paul Enferm 2006; 19(1): 82-7.

28. Dubet F. Le déclin de l'institution. Paris: Editions Du Seuil; 2002. 